\title{
Letter to the Editor: Reflections on: "Perioperative Management of Diabetes Mellitus: Novel Approaches"
}

\section{S. Raghuraman ${ }^{1}$}

Published online: 30 August 2019

(C) Springer Science+Business Media, LLC, part of Springer Nature 2019

\section{To the Editor:}

I read the review article of April 2019 issue, titled "Perioperative Management of Diabetes Mellitus: Novel Approaches" [1] with very much enthusiasm.

I greatly appreciate the authors for enlightening many readers like me on this topic which is not given much importance usually in many of the journals of this subject. Rather, it is unfortunate that the perioperative management of diabetes did not get the attention what it should have got in this century, as the burden of the disease has increased many folds in all parts of the world. Furthermore, the guidelines to manage the patients with diabetes perioperatively also did not change on the expected lines, i.e., from complexity to simplicity.

Although the novel approaches suggested in the review article [1] may not be possible for it to be executed in many places due to non-availability of concerned specialists as admitted by the authors also, it is worth noting some specific points that can be implemented in many places. For example, identifying the poor-risk cases based on the cut-off level of A1C preoperatively (suggested as eight, based on many studies on various populations) and managing them vigorously with more attention (albeit by any physicians) would pave the way for preventing many complications in this group of vulnerable patients. Another suggestion of avoiding the carbohydrate load as well as the intravenous dexamethasone (parts of enhanced recovery after surgery (ERAS) protocol) preoperatively is also noteworthy and can be adopted in any place. I also believe that this suggestion would avoid the compounding of the already existing problem of hyperglycemia, particularly in primary/secondary care settings where equipment/personnel are scarce.

M. S. Raghuraman

drraghuram70@gmail.com

1 Department of Anesthesiology, Sri Venkateshwaraa Medical College Hospital \& Research Centre, 13-A, Pondy-Villupuram Main Road, Ariyur, Puducherry 605102, India
The authors have mentioned under the "Postoperative period" heading that the target levels of glucose are 140$180 \mathrm{mg} / \mathrm{dl}$ and $100-180 \mathrm{mg} / \mathrm{dl}$ respectively for the intensive care and general floor patients as per the guidelines of American Diabetes Association (ADA) published in 2016. However, to my knowledge, there is no mentioning about the target value of $100-180 \mathrm{mg} / \mathrm{dl}$ for the general floor patients in those guidelines [2]. Indeed, as per the guidelines, higher ranges of glucose value, i.e., $>180 \mathrm{mg} /$ dl might be acceptable for in-patient care settings where frequent glucose estimation or close supervision by nursing staff is not feasible [2]. Hence, I am afraid that there is a potential chance of hypoglycemia in general floor patients if we adopt the target of $100-180 \mathrm{mg} / \mathrm{dl}$. It is mentioned in the same guidelines that the more accurate goal of $110-140 \mathrm{mg} / \mathrm{dl}$ might be appropriate for the selected group of critically ill patients such as cardiac surgery, acute cardiac, or neurological conditions [2].

Concerning the prevention of hypoglycemia, keeping the glucose target at $140-180 \mathrm{mg} / \mathrm{dl}$ would be helpful, because there is not much difference with regard to complications of hyperglycemia in intensive control regimen [3]. In addition, the incidences of mortality as well as hypoglycemia are higher in tight control regimen when compared to the moderate one [4]. The recent guidelines by French society also recommended a moderate target of $140-180 \mathrm{mg} / \mathrm{dl}$ [5].

It is irrefutable that the endocrinology team would significantly attenuate/abolish the incidence of hypoglycemia regardless of the regimens/goals of glucose value adopted. Nevertheless, close supervision by junior physicians/ paramedics, administering a combination of insulin and dextrose/basal insulin instead of variable rate infusion of insulin particularly for the general floor patients will reduce the occurrence of hypoglycemia in the absence of such team which may be the scenario in many patient care settings in developed countries too. 


\section{References}

1. Palermo NE, Garg R. Perioperative management of diabetes mellitus: novel approaches. Curr Diab Rep. 2019;19:14. https://doi. org/10.1007/s11892-019-1132-7.

2. American Diabetes Association. Diabetes care in the hospital. Diabetes Care. 2016;39(Supplement 1):S99-S104. https://doi.org/ $10.2337 / \mathrm{dc} 16-\mathrm{S} 016$.

3. Gandhi GY, Nuttall GA, Abel MD, Mullany CJ, Schaff HV, O'Brien $\mathrm{PC}$, et al. Intensive intraoperative insulin therapy versus conventional glucose management during cardiac surgery: a randomized trial. Ann Intern Med. 2007;146(4):233-43.
4. Duggan EW, Carlson K, Umpierrez GE. Perioperative hyperglycemia management: an update. Anesthesiology. 2017;126:547-60.

5. Cheisson $\mathrm{G}$, Jacqueminet $\mathrm{S}$, Cosson $\mathrm{E}$, Ichai $\mathrm{C}$, Leguerrier $\mathrm{AM}$, Nicolescu-Catargi B, et al. Perioperative management of adult diabetic patients.Intraoperative period. Anaesth Crit Care Pain Med. 2018;37(Suppl 1):S21-5. https://doi.org/10.1016/j.accpm.2018.02.018.

Publisher's note Springer Nature remains neutral with regard to jurisdictional claims in published maps and institutional affiliations. 